\title{
Article \\ Impact of the Type of Dialysis on Time to Transplantation: Is It Just a Matter of Immunity?
}

\author{
Matteo Righini ${ }^{1,2} \oplus$, Irene Capelli ${ }^{1}$, Marco Busutti ${ }^{1}$, Concettina Raimondi ${ }^{1}$, Giorgia Comai ${ }^{1}$, Gabriele Donati ${ }^{1}$, \\ Maria Laura Cappuccilli $\left.{ }^{3}{ }^{(}\right)$, Matteo Ravaioli $\left.{ }^{4}{ }^{(}\right)$, Pasquale Chieco ${ }^{3}$ and Gaetano La Manna ${ }^{1, *}$ \\ 1 Nephrology, Dialysis and Transplantation Unit, IRCCS-Azienda Ospedaliero Universitaria di Bologna, \\ Alma Mater Studiorum, University of Bologna, 40100 Bologna, Italy; matteo.righini5@unibo.it (M.R.); \\ irene.capelli@gmail.com (I.C.); marco.busutti@live.it (M.B.); concettina.raimondi@aosp.bo.it (C.R.); \\ giorgia.comai@aosp.bo.it (G.C.); gabriele.donati@aosp.bo.it (G.D.) \\ 2 Nephrology and Dialysis Unit, Santa Maria delle Croci Hospital, 48100 Ravenna, Italy \\ 3 Department of Experimental, Diagnostic and Specialty Medicine (DIMES), University of Bologna, \\ 40126 Bologna, Italy; maria.cappuccilli@unibo.it (M.L.C.); pasquale.chieco@unibo.it (P.C.) \\ 4 Department of General Surgery and Transplantation, Policlinico di Sant' Orsola, 40138 Bologna, Italy; \\ matteo.ravaioli@aosp.bo.it \\ * Correspondence: gaetano.lamanna@unibo.it; Tel.: +39-0512143255; Fax: +39-051340871
}

check for

updates

Citation: Righini, M.; Capelli, I.; Busutti, M.; Raimondi, C.; Comai, G.; Donati, G.; Cappuccilli, M.L.; Ravaioli, M.; Chieco, P.; La Manna, G. Impact of the Type of Dialysis on Time to Transplantation: Is It Just a Matter of Immunity?. J. Clin. Med. 2022, 11, 1054. https://doi.org/ $10.3390 /$ jcm 11041054

Academic Editor: Eytan Mor

Received: 20 January 2022

Accepted: 16 February 2022

Published: 17 February 2022

Publisher's Note: MDPI stays neutral with regard to jurisdictional claims in published maps and institutional affiliations.

Copyright: (C) 2022 by the authors. Licensee MDPI, Basel, Switzerland. This article is an open access article distributed under the terms and conditions of the Creative Commons Attribution (CC BY) license (https:// creativecommons.org/licenses/by/ $4.0 /)$.

\begin{abstract}
Background: Renal transplantation represents the therapeutic gold standard in patients with end stage renal disease (ESRD). Still the role of pre-transplant dialysis in affecting time to transplantation has yet to be determined. We wanted to verify whether the type of renal replacement therapy (hemodialysis vs. peritoneal dialysis) affects time to transplantation and to identify clinical features related to the longer time to transplantation. Methods: We performed a retrospective singlecenter observational study on patients who had received a transplant in the Bologna Transplant Unit from 1991 to 2019, described through the analysis of digital transplant list documents for sex, age, body mass index (BMI), blood group, comorbidities, underlying disease, serology, type of dialysis, time to transplantation, Panel Reactive Antibodies (PRA) max, number of preformed anti Human Leukocyte Antigens (HLA) antibodies. A p-value $<0.05$ was considered statistically significant. Results: In the 1619 patients analyzed, we observed a significant difference in time to transplant, PRA max and Preformed Antibodies Number between patients who received Hemodialysis (HD) and Peritoneal dialysis (PD). Then we performed a multiple regression analysis with all the considered factors in order to identify features that support these differences. The clinical variables that independently and directly correlate with longer time to transplantation are PRA max $(p<0.0001)$, Antibodies number $(p<0.0001)$ and HD $(p<0.0001)$; though AB blood group $(p<0.0001)$, age $(p<0.003)$ and PD $(p<0.0001)$ inversely correlate with time to transplantation. Conclusions: In our work, PD population received renal transplants in a shorter period of time compared to HD and turned out to be less immunized. Considering immunization, the type of dialysis impacts both on PRA max and on anti HLA antibodies.
\end{abstract}

Keywords: peritoneal dialysis; hemodialysis; kidney transplantation; autoimmunity

\section{Introduction}

Hemodialysis (HD) and Peritoneal Dialysis (PD) are the two most common forms of renal replacement therapy, life-saving treatment for patients with End Stage Renal Disease (ESRD). Despite there being contraindications for each treatment, nowadays the choice of the kind of treatment depends on several features, mainly the specific experience of the Clinical Unit and the patient's choice [1]. Although PD is a well-established treatment modality it is underused in Western countries, with a prevalence in Italy of $15 \%[2,3]$. Recently, several studies showed a relative survival advantage for patients receiving PD lasting one to two years after dialysis initiation [4-8]. Renal transplantation represents the 
therapeutic "gold standard" in patients with ESRD ensuring better outcomes compared with dialysis both in patient survival and quality of life [2,9-11]. The role of pre-transplant dialysis choice in affecting transplant outcomes has been the subject of long-standing interest [12-15]. For those who could not stand the prospect of living donor transplantation, being on the waiting list for kidney transplantation from a deceased donor is a vital choice. According to CNT (National Transplant Centre) data, in our country a patient who signs up for renal transplant waiting list normally waits 3.3 years before getting a transplant [16]. There are several known demographic and clinical factors that affect time to transplantation (age, blood group, and level of antibody sensitization) [14] but many other factors are implied.

We wanted to verify whether the type of renal replacement therapy (HD vs. PD) affects time to transplantation and we wanted to identify clinical features related to longer time to transplantation.

\section{Materials and Methods}

We performed a retrospective study on patients who have received a transplant in the Bologna Transplant Unit from 1991 to 2019, described through the analysis of digital transplant list documents for sex, age, BMI, blood group, hypertension, diabetes, cardiovascular disease, neoplastic disease, underlying disease, serology (HBV, HCV, HIV, CMV, Toxo, EBV, LUE), type of dialysis, time to transplantation, Panel Reactive Antibodies (PRA max), and number of preformed anti Human Leukocyte Antigens (HLA) antibodies. Immunologic data were collected regarding typing of HLA, PRA max that represent the maximal value of PRA in the considered waiting time to transplant. PRA was expressed as the percentage of lymphocyte panel members against which the patient's serum reacts and thus against which the patient has HLA class I or II antibodies. Since 2012 all the PRA was tested with the complement-dependent cytotoxicity test (PRA-CDC) for monitoring the degree of immunization in kidney transplant candidates on active waiting lists, after that year patients were tested with the use of Labscreen PRA class I and II on a Luminex platform. The number of preformed antibodies expressed the quantity of specific preformed HLA class I or II that the recipient patient presented. Levels of normalized, mean fluorescence intensity $>1000$ were considered to be positive.

We excluded patients who had received a previous transplant, who were recorded in the national hyperimmune program supposing that those patients were too immunized and they have been on the waiting list a very long time, patients transplanted or signed up in pre-emptive modality, and patients who received a combined transplant (Figure 1).

We used survival curves to analyze time to transplantation with transplantation as an end point.

Data were taken from the digital medical records and was imported to create a database specifically for the study. The study was approved by the Local Ethical Committee. 


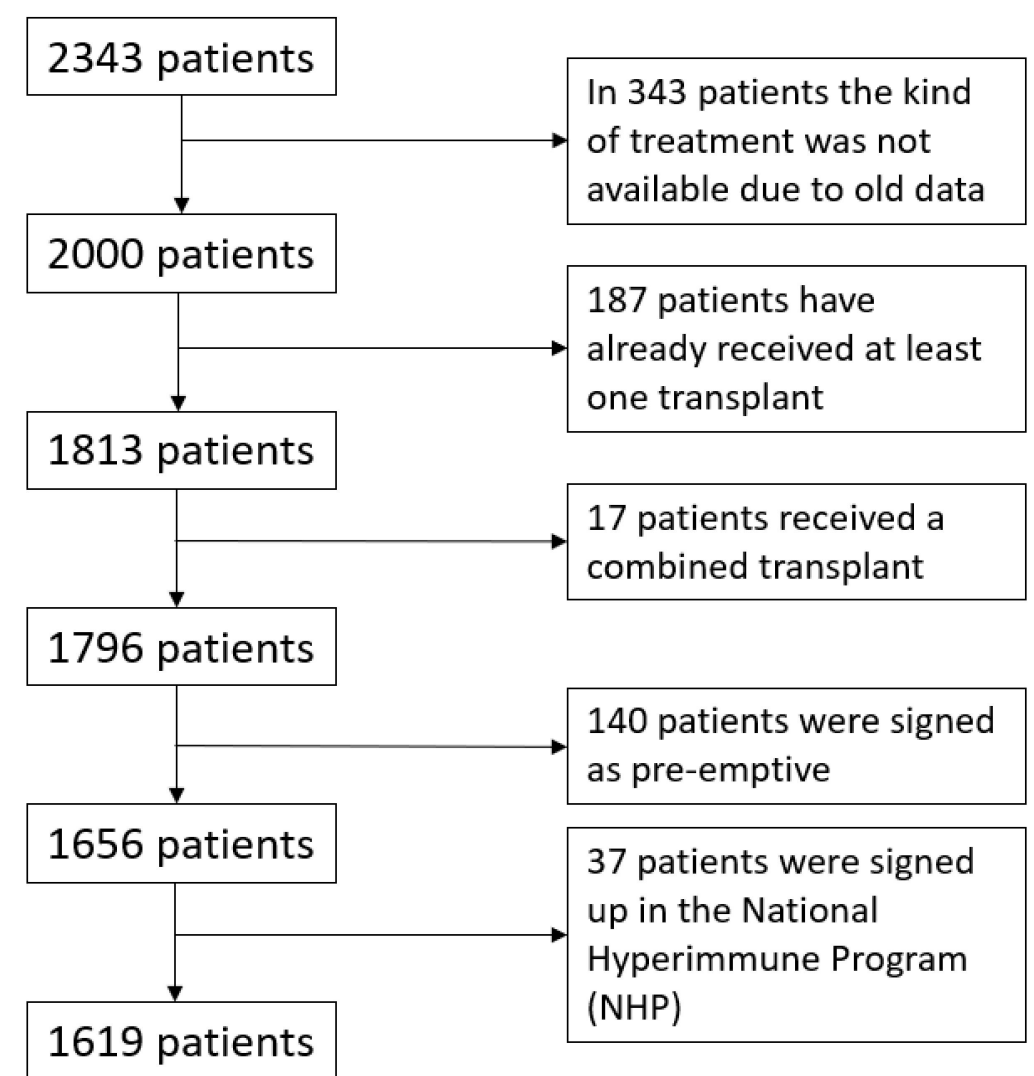

Figure 1. Patients who received a kidney transplant in Bologna Transplant Unit between 1991 and 2019 and exclusion criteria.

\section{Statistical Analysis}

The aim of statistical analysis in this observational study was to find factors associated with time to transplantation. The proper test of statistical significance depends on the nature of the examined variables. Student's $t$-test or ANOVA followed by Tukey post-hoc test, corrected for heteroscedasticity, when necessary, were used for real outcome variables. For non-parametric outcomes we used Mann-Whitney test or Kruskal-Wallis ANOVA followed by Dunn's test for pair-wise comparisons. Categorical data were analyzed using contingency tables and $\chi^{2}$. Linear associations using one or more covariate were explored with linear regression. Survival curves were computed by Kaplan-Meier estimate [17] and compared by a log-rank test. Continuous variables are presented as mean \pm Standard Deviation or as median and Interquartile interval (IQR) when appropriated. All statistical tests were two-tailed, and we used JMP 13 (SAS Institute Inc., Cary NC, USA) for data management and analysis. $p$-values were not corrected for multiplicity and the findings should be interpreted as exploratory. A $p$-value $<0.05$ was considered statistically significant.

\section{Results}

We considered in our analysis 2343 patients who received a transplant in Bologna from 1991 to 2019. According to exclusion criteria (Figure 1), we analyzed 1619 patients. As is shown in Table 1, our population presented $1053(65 \%)$ men, mean age at transplantation was $61.9 \pm 12.4$ years, mean years of dialysis before transplantation were $4.4 \pm 6.5$ years (1618.34 \pm 2376.75 days), 554 (34.2\%) patients had hypertension, $214(13.2 \%)$ had diabetes, $79(4.9 \%)$ had cardiovascular disease, $18(1.1 \%)$ had a history of neoplastic disease. Mean BMI was $24.1 \pm 3.5$. There were 1347 patients who received HD and 271 (16.7\%) received $\mathrm{PD}$, latency from the beginning of dialysis to the enrolment on the transplant waiting list resulted in 354.5 days (IQR 108.6 days); 901 (55.6\%) patients presented with $\mathrm{HbsAb}$; 1037 (64\%) patients had positive CMV IgG; 653 (40.3\%) patients had Blood Group A; 
180 (11.1\%) had B; 705 (43.5\%) had 0; and only 78 (4.8\%) had AB. In our cohort $169(10.4 \%)$ patients had IgA nephropathy; 161 (9.9\%) had hypertensive nephropathy; $328(20.3 \%)$ presented with Polycystic Kidney Disease; 153 (9.4\%) had Diabetic Nephropathy; 374 (23.1\%) patients presented with other nephropathies while 433 (26.7\%) patients had an unknown diagnosis. In total, 554 patients presented with hypertension. Mean time to transplantation was $2.4 \pm 2.6$ years (889.3 \pm 945.7 days), PRA max resulted in $21.04 \pm 31.5$ and number of preformed antibodies resulted in $4.6 \pm 12.9$.

Table 1. Features of the study population and according to the type of dialysis.

\begin{tabular}{|c|c|c|c|c|}
\hline & Population & Hemodialysis & Peritoneal Dialysis & $p$ Value \\
\hline No. of patients & 1619 & $1347(83.2 \%)$ & $271(16.8 \%)$ & \\
\hline \multicolumn{5}{|l|}{ Sex } \\
\hline - $\quad$ Male & $1053(65 \%)$ & $898(66.7 \%)$ & $155(57.2 \%)$ & \multirow{2}{*}{$0.002 *$} \\
\hline - $\quad$ Female & $565(35 \%)$ & $449(33.3 \%)$ & $116(42.8 \%)$ & \\
\hline Age (years) & $61.9 \pm 12.4$ & $61.9 \pm 12.3$ & $62.2 \pm 12.5$ & ns \\
\hline \multicolumn{5}{|l|}{ Blood group } \\
\hline - $\mathrm{A}$ & $651(40.2 \%)$ & $533(39.6 \%)$ & $118(43.5 \%)$ & \multirow{4}{*}{$0.007 *$} \\
\hline - $\quad \mathrm{B}$ & $179(11.1 \%)$ & $150(11.1 \%)$ & $29(10.7 \%)$ & \\
\hline - $\quad \mathrm{AB}$ & $76(4.7 \%)$ & $54(4 \%)$ & $22(8.1 \%)$ & \\
\hline & $705(43.5 \%)$ & $605(44.9 \%)$ & $100(36.9 \%)$ & \\
\hline BMI & $24.1 \pm 3.5$ & $23.9 \pm 3.5$ & $24.7 \pm 3.4$ & $0.001 *$ \\
\hline Diabetes & $214(13.2 \%)$ & $182(13.5 \%)$ & $32(11.8 \%)$ & ns \\
\hline Hypertension & $554(34.2 \%)$ & $452(33.6 \%)$ & $102(37.6 \%)$ & ns \\
\hline Cardiovascular disease & $79(4.9 \%)$ & $56(4.2 \%)$ & $23(8.5 \%)$ & ns \\
\hline Neoplastic disease & $18(1.1 \%)$ & $15(1.1 \%)$ & $3(1.1 \%)$ & ns \\
\hline \multicolumn{5}{|l|}{ Nephropathy } \\
\hline \multirow{6}{*}{$\begin{array}{ll}\text { - } & \text { Unknown } \\
\text { - } & \text { IgA nephropathy } \\
\text { - } & \text { Hypertensive } \\
\text { - } & \text { ADPKD } \\
\text { - } & \text { Diabetic } \\
\text { - } & \text { Other }\end{array}$} & $433(26.7 \%)$ & $366(27.2 \%)$ & $67(24.7 \%)$ & \multirow{6}{*}{ ns } \\
\hline & $169(10.4 \%)$ & $138(10.2 \%)$ & $31(11.4 \%)$ & \\
\hline & $161(9.9 \%)$ & $127(9.4 \%)$ & $34(12.5 \%)$ & \\
\hline & $328(20.3 \%)$ & $284(21.1 \%)$ & $44(16.2 \%)$ & \\
\hline & $153(9.4 \%)$ & $126(9.3 \%)$ & $27(10 \%)$ & \\
\hline & $374(23.1 \%)$ & $306(22.7 \%)$ & $68(25.1 \%)$ & \\
\hline
\end{tabular}

Prior time of dialysis until listing for transplantation Med [IQR]

\begin{tabular}{lcccc}
\hline $\mathrm{HCV}$ IgG & $61(3.8 \%)$ & $58(4.3 \%)$ & $3(1.1 \%)$ & $\mathrm{ns}$ \\
\hline $\mathrm{HBs} \mathrm{Ab}$ & $901(55.6 \%)$ & $753(55.9 \%)$ & $148(54.6 \%)$ & $\mathrm{ns}$ \\
\hline $\mathrm{HbcAb}$ & $220(13.6 \%)$ & $186(13.8 \%)$ & $34(12.5 \%)$ & $\mathrm{ns}$ \\
\hline $\mathrm{CMV} \mathrm{IgG}$ & $1037(64.1 \%)$ & $839(62.3 \%)$ & $198(73.1 \%)$ & $\mathrm{ns}$
\end{tabular}

PRA max $(\%)$

$\begin{array}{llccc}- & 0 & 477(29.5 \%) & & 127(46.9 \%) \\ -1-19 & 472(29.1 \%) & 350(26 \%) & 77(28.4 \%) \\ \text { - } \quad 20-79 & >80 & 258(15.9 \%) & 395(29.3 \%) 230(17.1 \%) & 28(10.3 \%) \\ \text { - } & 157(9.7 \%) & 145(10.8 \%) & 12(4.4 \%)\end{array}$

Features of the study population described as Sex, Age at the time of transplantation, BMI, underlying nephropathy, prior time of dialysis until listing for transplantation, serology for $\mathrm{HCV}, \mathrm{HBV}$ and $\mathrm{CMV}$. Cardiovascular disease was considered as patients who had heart failure or previous myocardial infarction. All the variables were compared through Student's $t$-test or ANOVA followed by Tukey post-hoc test, corrected for heteroscedasticity. BMI: Body Mass Index. ADPKD: Autosomic Dominant Polycystic Kidney Disease. * A $p$ value was considered significant when $p<0.05$. 
As previously described, we aimed to analyze whether the type of dialysis could influence time to transplant. Indeed, we observed a significant difference in time to transplant (933 \pm 25.6 days in HD and $667.3 \pm 57.1$ days in PD, $p<0.001)$, PRA max $(23.1 \pm 0.9$ in HD and $11.4 \pm 1.9$ in PD, $p<0.001)$ and Preformed Antibodies Number $(5.1 \pm 0.3$ in HD and $2 \pm 0.7$ in PD, $p<0.001)$ between patients who received HD and PD. Then we performed a multiple regression analysis with all the considered factors in order to identify features that support these differences. In Table 2 the clinical variables that independently and directly correlates with longer time to transplantation are listed: PRA max $(p<0.0001)$, Antibodies number $(p<0.0001)$ and HD $(p<0.0001)$. Other features inversely correlate with time to transplantation: AB blood group $(p<0.0001)$, age $(p<0.003)$ and PD $(p<0.0001)$.

Table 2. Multiple regression for Time to transplant.

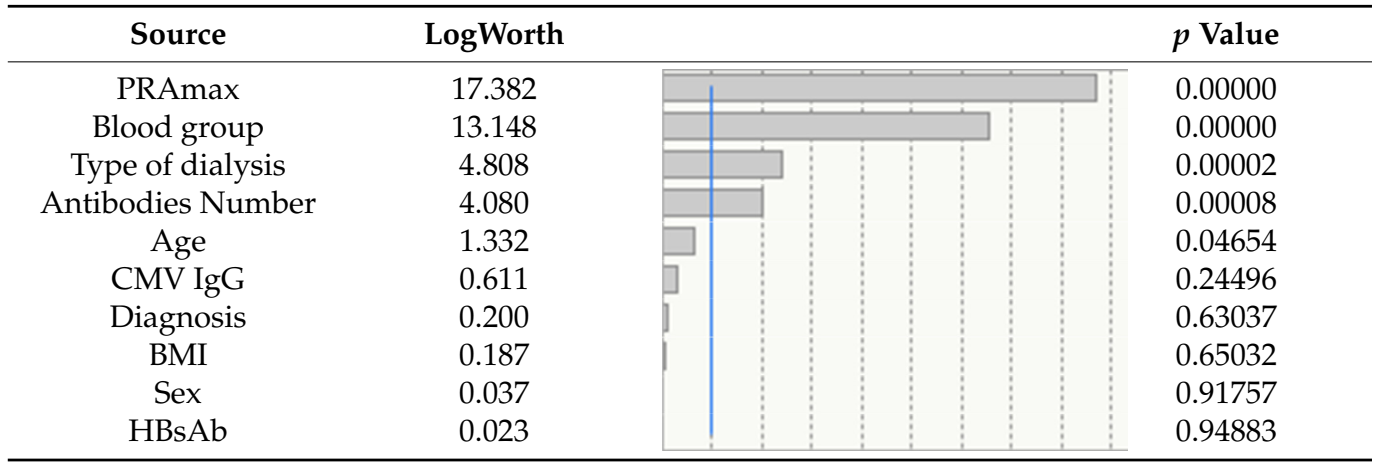

We can observe that the variables that directly correlate with time to transplantation are PRA max, Antibodies Number and HD; factors that inversely correlate are AB blood group, age and PD. These results are confirmed even in the Multivariate analysis. PRA = Panel Reactive Antibodies. HD = Hemodialysis. PD = Peritoneal Dialysis.

Assuming that immunization is a key factor in determining time to transplant, though we analyzed our PRA max data according to the model that Bostock et al. used [18] (Figure 2). Then we performed a multiple regression on PRA max: the only parameters that correlate with PRA max values are the type of dialysis $(p=0.0015)$, AB blood group $(p=0.0017)$ and BMI $(p=0.0079)$ (Table 3$)$. Another way to describe immunization is through antibodies' expression: as shown in Table 4, in performing a multiple regression analysis on antibodies number we evidenced that the only features that correlate with a higher number of pre-formed antibodies were age $(p=0.0001)$ and type of dialysis $(p=0.0004)$.

Table 3. Multiple regression for PRA max.

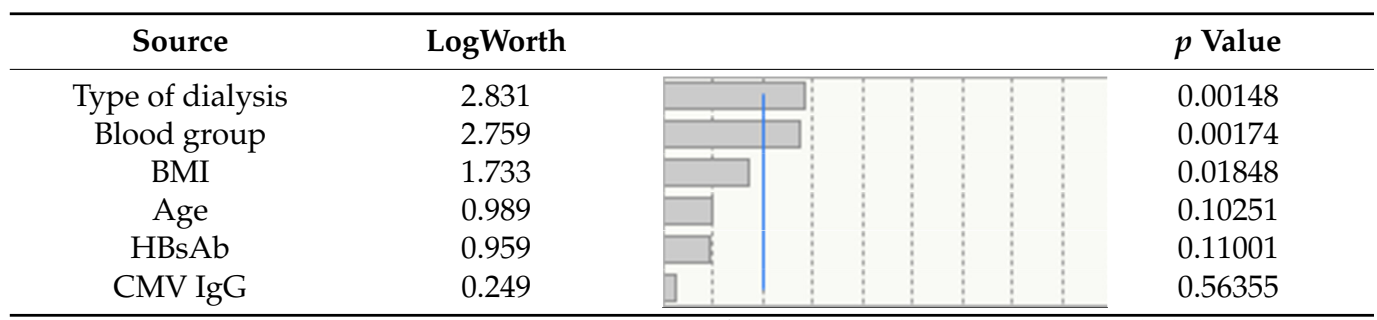

Factors that correlate with elevated PRA max are Type of dialysis, AB blood group and, slightly, BMI. These factors are confirmed even in the multivariate analysis.

Considering time to transplantation to be our first goal we represent our results in Figure 3. Then we created subgroups according to Age, BMI, Blood Group, and Diagnosis, exploring whether these differences persisted in all the subgroups. Data are presented in Table 3. 
Table 4. Multiple regression for Antibodies Number.

\begin{tabular}{|c|c|c|c|}
\hline Source & LogWorth & & $p$ Value \\
\hline Age & 2.771 & E & 0.00169 \\
\hline Type of dialysis & 1.985 & & 0.01034 \\
\hline BMI & 0.812 & $\square$ & 0.15432 \\
\hline $\mathrm{HBsAb}$ & 0.784 & $\square$ & 0.16447 \\
\hline Blood Group & 0.407 & $\square$ & 0.39161 \\
\hline CMV IgG & 0.197 & ] & 0.63481 \\
\hline
\end{tabular}

Factors that correlate with Antibodies Number are Type of dialysis and Age. These factors are confirmed even in the multivariate analysis.

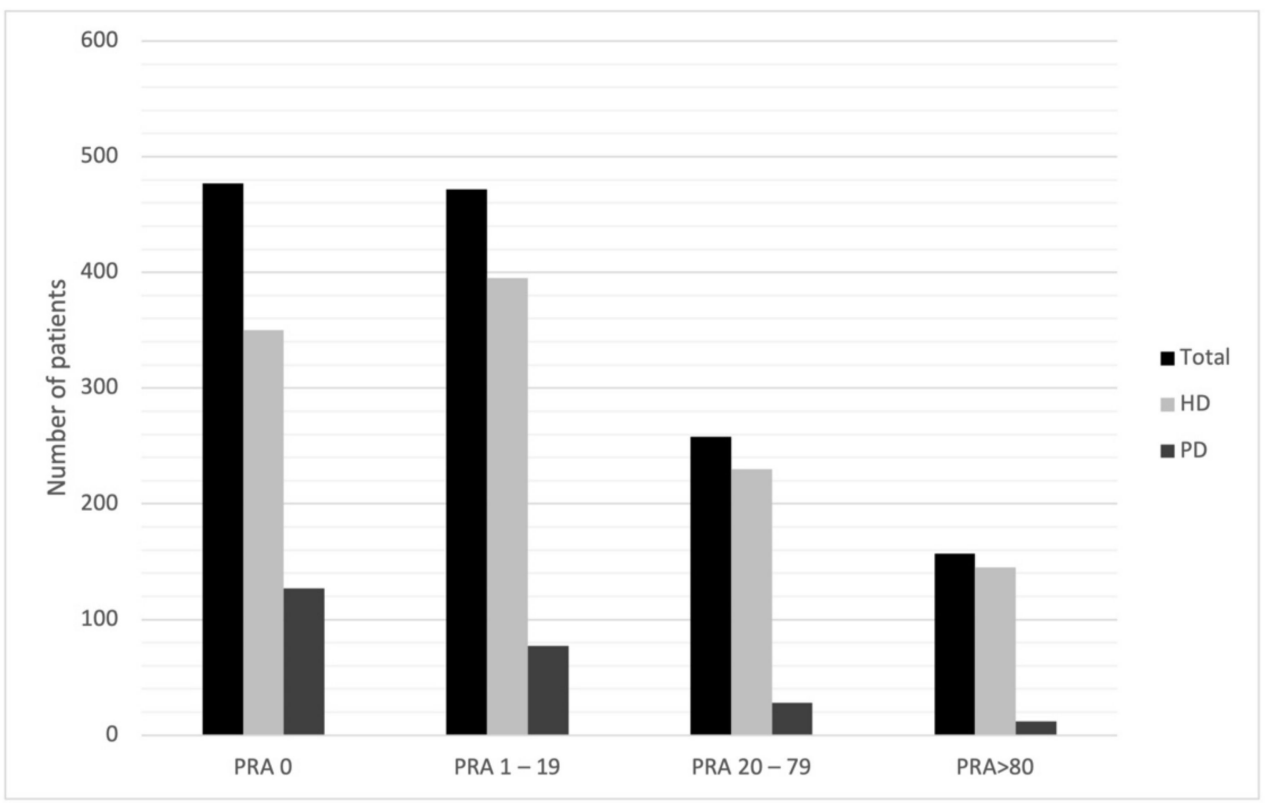

Figure 2. Patients divided according to PRA max. The classes were selected according to the study conducted by Bostock IC et al. [18]. HD: hemodialysis. PD: peritoneal dialysis.

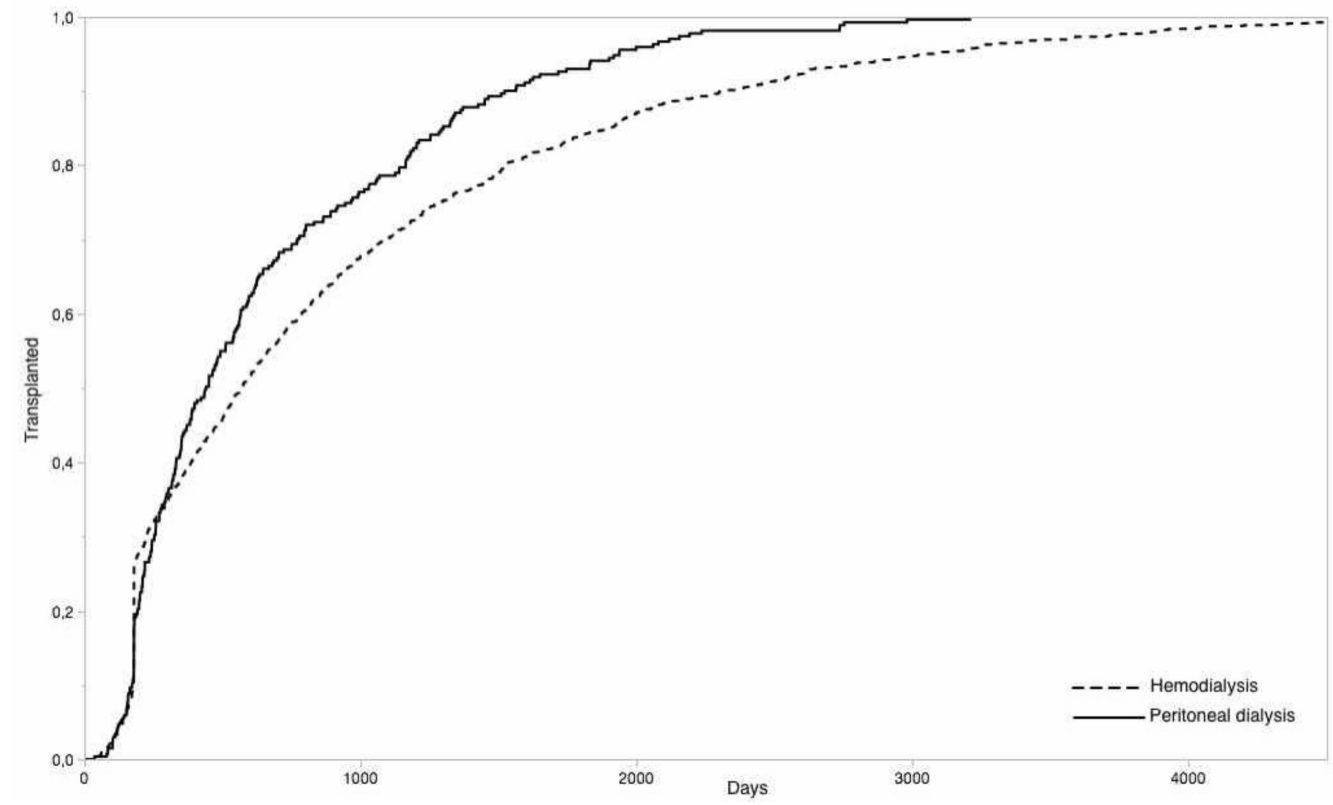

Figure 3. Patients who received kidney transplant divided by type of dialysis. Those who received PD (271 patients) reached the goal (kidney transplant) far earlier than those who received HD (1347 patients) (Log-Rank ChiSquare 21.99, $p<0.0001$, Wilcoxon ChiSquare 5.77, $p=0.0163$ ). 
4.1. Age

Considering age, we analyzed the population divided into 5 groups: Group 1 Age $\leq 45$; Group $245<$ Age $\leq 55$; Group $355<$ Age $\leq 65$; Group $465<$ Age $\leq 75$; Group 5 Age $>75$. In the HD population we found significant differences between group 3 (1117 \pm 49.4 days) and $5(680.4 \pm 72.9$ days, $p<0.0001)$, and between group 3 and $4(854.5 \pm 50.4$ days, $p=0.002)$.

In the PD population we pointed out significant differences only between group 2 (815.1 \pm 84.4 days) and 4 (521.1 \pm 60.9 days, $p=0.04)$.

Considering age to be a factor that independently correlates with Antibodies number, we performed the same analysis, showing that in the HD population there existed a significant difference between group $2(7.2 \pm 0.9)$ and group $5(1.9 \pm 1, p<0.001)$; group 1 $(6.8 \pm 1.2)$ and group $5(p<0.01)$; group $3(5.9 \pm 0.7)$ and group $5(p<0.01)$; and group 2 and group $4(3.8 \pm 0.7, p<0.02)$. Conversely, in the PD population we evidenced no differences.

\subsection{BMI}

Considering BMI, we analyzed the two populations divided into 4 groups: Group 1 $\mathrm{BMI} \leq 20$, Group $220<\mathrm{BMI} \leq 25$, Group $325<\mathrm{BMI} \leq 30$, Group $4 \mathrm{BMI}>30$. We did not found any significant difference among groups both in HD as in PD.

Since BMI resulted in an independent factor that influenced PRA max, we performed the same analysis showing that in the HD group there existed significant differences between group $1(26.1 \pm 33.5)$ and group $2(20.2 \pm 30.6, p<0.048)$, and between group 1 and group $3(19.2 \pm 28.7, p<0.02)$. In the PD population we highlighted no differences among groups.

\subsection{Blood Group}

Considering blood group, we analyzed the population according to the 4 groups: $\mathrm{A}, \mathrm{AB}, \mathrm{B}, \mathrm{O}$. In the HD population we evidenced significant differences between 0 (1124.5 \pm 39.7 days) and $\mathrm{AB}(426 \pm 131.7$ days, $p<0.0001), \mathrm{B}(957.3 \pm 79.5$ days $)$ and $\mathrm{AB}(p=0.003), 0$ and $\mathrm{A}(765.2 \pm 42.3$ days, $p<0.0001)$. The difference between $\mathrm{A}$ and $\mathrm{AB}$ is nearly significant $(p=0.06)$. In the PD group differences occurred between $\mathrm{O}$ $(840.3 \pm 59$ days $)$ and $\mathrm{AB}(433.9 \pm 122.9$ days, $p=0.01)$ and between $\mathrm{O}$ and $\mathrm{A}(590.1 \pm 54$ days, $p=0.01$.

Since blood group represented a category that influence the PRA max, we performed the same group analysis but we did not evidence differences both in HD as in PD.

Between HD and PD there existed in our whole population a significant difference in PRA max for the A group (mean HD PRAmax $20.7 \pm 1.4$, mean PD PRAmax $8.9 \pm 2.9$, $p=0.0004$ ), AB group (mean HD PRAmax $22.2 \pm 4.2$, mean PD PRAmax $3 \pm 6, p=0.01$ ) and O group (mean HD PRAmax $25.9 \pm 1.4$, mean PD PRAmax $15.1 \pm 3.4, p=0.003$ ).

\subsection{Diagnosis}

Considering diagnosis, we analyzed the population divided into 6 groups: $\operatorname{IgA}$ nephropathy, Hypertensive, ADPKD, Diabetic, Other nephropathies, Unknown origin.

Both in the HD as in the PD population we evidenced no differences among groups.

Considering that ESA could have substantially reduced the use of blood transfusions, we divided our population in two groups, before 2000 (old group) and after 2000 (new group), considering that ESA were introduced in 1990 and in the following years achieved global distribution. We compared the Antibodies numbers of two groups showing that there was no significant difference (HD group $p=0.068, \operatorname{PD}$ group $p=0.290$ ) but the statistical difference remained if we compared the HD old group vs. PD old group $(p=0.029)$ and the HD new group vs. PD new group $(p=0.018)$.

\section{Discussion}

Prolonged dialysis exposure casts a long shadow and negatively impacts patient and graft survival even after transplantation [19-21]. Despite similar results in terms of outcome, 
PD is far less used as renal replacement therapy compared to HD [2,3]. Decisions regarding dialysis choice should be individualized, considering several important outcomes including patient survival and quality of life. A study conducted by Heaf et al. analyzed the relative survival of PD compared to HD, showing that PD has a relatively better prognosis for younger and non-diabetic patients, and for no subgroup was worse than HD; one possible cause is the better preservation of residual renal function in PD [22,23]. A shorter time to transplant could be one of the drives that lead the patient's choice. Several studies analyzed kidney transplant outcomes according to dialysis modality; most studies revealed that PD was associated with shorter time on dialysis, better graft and patient survival [24-31].

Recent works reported that the transplant list waiting time is reduced in PD compared to those on HD $[13,15]$ and the results in our cohort confirm this data. What causes these differences is yet to be proven: some explanations can be hypothesized.

As reported by several studies, sensitization is a known barrier to transplantation and sensitized patients have substantially longer waiting times; the breadth of sensitization against HLAs is routinely monitored in wait-listed patients with ESRD using panel reactive antibody (PRA) assays [32-35]. Previous transplant, in addition to pregnancies and blood transfusions, is a known cause of immune sensitization against "non-self" human leukocyte antigens (HLAs). Moreover, PRA is an independent predictor of mortality in wait-listed kidney transplant candidates [36]. There is good epidemiologic evidence showing a direct relationship between pretransplant PRA levels and adverse graft outcomes [37-39]. Our study confirms that an elevated PRA is associated with longer time to transplant, but also shows that even patients on PD have a lower mean PRA compared to those on HD $(p<0.0001)$.

Considering anti-HLA antibodies, our study shows that they are related to an increased time to transplantation, as supported by a large cohort study, where the authors suggest that anti-HLA antibodies are associated with an increased sensitization and mortality in waitlisted kidney transplant candidates [36]. In our cohort, PD patients presented less anti-HLA antibodies than HD patients $(p<0.001)$. A reason may lie in the fact that HD patients had a greater tendency to anemia and more likely may require blood transfusions, which can determine an increase in panel reactive antibody percentage $[15,40]$. Other explanations may be further investigated. Our results suggest that BMI is a factor that influences kidney transplant recipient immunization. Lots of studies have investigated obesity in kidney transplant recipients, recognizing its importance as a risk factor for chronic allograft dysfunction, exposing to a major risk of delayed graft function and considering some cases an exclusion criteria for transplantation [41-43]. Several mechanisms exert negative metabolic effects of raised BMI and adiposity, and recent studies demonstrated that higher BMI was associated with higher inflammation, that correlates with mortality [44-46].

Indeed, in our cohort, PD patients presented a significantly reduced waiting time for kidney transplant even eliminating the impact of immunization: so we have to wonder that other non-immunological factors may have an impact on this result.

Patients who undergo PD tend to be more empowered, to have a strong social support network and to pursue their care plan by themselves [47]. Moreover, our PD group had a lower pretransplant dialysis vintage compared with the HD group (PD 225-271.8 vs. HD 383-118.3, $p=0.06$ ), leading to a different exposure to dialysis-related immune dysfunction. Nonetheless, the latency from the beginning of dialysis to the enrolment on the transplant waiting list resulted in differences between the PD group and the HD group, though nearly significant $(p=0.06)$. This could once more be explained by the strong social support network of patients who chose PD.

Age is a considering factor in transplant recipients and up to twenty years ago, lots of patients would have been excluded due to being elderly. The "old to old" allocation system in the Eurotransplant $[48,49]$ community has shown to be effective in increasing the number of transplants; thus, in our population 45 to 65 years old patients were the most represented age groups, therefore they present a longer mean time to transplantation. These results are in line with literature [50]. 
Regarding the relationship between blood groups and time to transplant, Chang et al. [51] reported that blood group $\mathrm{AB}$ have the highest likelihood of deceased donor transplantation, followed by patients with blood groups A, O and B; within blood groups, the likelihood of transplantation was inversely related to the level of sensitization (PRA max). Our study confirms previous work showing longer waiting times for blood group $O$ patients $[14,52]$ and that $\mathrm{AB}$ recipients were more likely to receive deceased donor kidneys [53]. Thus, $\mathrm{AB}$ patients represent a small population, though not sufficient to draw conclusions on time to transplant.

Our study presents some limitations: in addition to the retrospective nature of the analysis due to the long-considered time and to patients' dialysis center variability, the precise number of blood transfusions was not available. Since the study covers 30 years of experience, variability in dialysis practice (HD vs. PD) between different referral centers made the population less homogeneous.

\section{Conclusions}

In our work, the PD population received renal transplant in a shorter period of time compared to the HD, turned out to be less immunized, considering immunization to be the number of antibodies and PRA. Time to transplant is mostly a matter of immunity but other factors can influence it, such as age, blood group and type of dialysis. Considering immunization, the type of dialysis impacted both on PRA max (together with BMI and blood group) as on anti HLA antibodies (together with age). Our study supports the choice of PD for patients who can afford it, particularly for those who would like to receive a kidney transplant.

Author Contributions: M.R. (Matteo Righini), I.C. and C.R. designed the work, M.R. (Matteo Righini); I.C. and M.B. researched literature and conceived the study. G.D., G.C. and M.R. (Matteo Ravaioli) were involved in patients' recruitment and data interpretation; M.L.C. revised the English language and performed statistical analysis; P.C. performed the statistical analysis; M.R. (Matteo Righini), I.C., M.B. and P.C. wrote the first draft of the manuscript; G.L.M. revised the work critically and revised data interpretation. All authors have read and agreed to the published version of the manuscript.

Funding: This research received no specific grant from any funding agency in the public, commercial, or not-for-profit sectors.

Institutional Review Board Statement: The study was conducted in accordance with the principles of the Declaration of Helsinki and was approved by the local Ethical Committee.

Informed Consent Statement: All the patients signed an informed consent when they entered on the transplant list. The informed consent, according to the national and regional transplantation protocol, let the data be used for research.

Data Availability Statement: Data can be found on the Donor Manager transplant program.

Conflicts of Interest: The authors declare no conflict of interest.

\section{References}

1. Desai, A.A.; Bolus, R.; Nissenson, A.; Bolus, S.; Solomon, M.D.; Khawar, O.; Gitlin, M.; Talley, J.; Spiegel, B.M. Identifying best practices in dialysis care: Results of cognitive interviews and a national survey of dialysis providers. Clin. J. Am. Soc. Nephrol. CJASN 2008, 3, 1066-1076. [CrossRef]

2. Khawar, O.; Kalantar-Zadeh, K.; Lo, W.K.; Johnson, D.; Mehrotra, R. Is the declining use of long-term peritoneal dialysis justified by outcome data? Clin. J. Am. Soc. Nephrol. CJASN 2007, 2, 1317-1328. [CrossRef] [PubMed]

3. Zaza, G.; Rugiu, C.; Trubian, A.; Granata, S.; Poli, A.; Lupo, A. How has peritoneal dialysis changed over the last 2015,30 years: Experience of the Verona dialysis center. BMC Nephrol. 2015, 16, 53. [CrossRef] [PubMed]

4. Weinhandl, E.D.; Foley, R.N.; Gilbertson, D.T.; Arneson, T.J.; Snyder, J.J.; Collins, A.J. Propensity-matched mortality comparison of incident hemodialysis and peritoneal dialysis patients. J. Am. Soc. Nephrol. 2010, 21, 499-506. [CrossRef] [PubMed]

5. Quinn, R.R.; Hux, J.E.; Oliver, M.J.; Austin, P.C.; Tonelli, M.; Laupacis, A. Selection bias explains apparent differential mortality between dialysis modalities. J. Am. Soc. Nephrol. 2011, 22, 1534-1542. [CrossRef]

6. Yeates, K.; Zhu, N.; Vonesh, E.; Trpeski, L.; Blake, P.; Fenton, S. Hemodialysis and peritoneal dialysis are associated with similar outcomes for end-stage renal disease treatment in Canada. Nephrol. Dial. Transplant. 2012, 27, 3568-3575. [CrossRef] [PubMed] 
7. Vonesh, E.F.; Snyder, J.J.; Foley, R.N.; Collins, A.J. The differential impact of risk factors on mortality in hemodialysis and peritoneal dialysis. Kidney Int. 2004, 66, 2389-2401. [CrossRef]

8. Termorshuizen, F.; Korevaar, J.C.; Dekker, F.W.; Van Manen, J.G.; Boeschoten, E.W.; Krediet, R.T. Hemodialysis and peritoneal dialysis: Comparison of adjusted mortality rates according to the duration of dialysis: Analysis of The Netherlands Cooperative Study on the Adequacy of Dialysis 2. J. Am. Soc. Nephrol. 2003, 14, 2851-2860. [CrossRef] [PubMed]

9. Wolfe, R.A.; Ashby, V.B.; Milford, E.L.; Ojo, A.O.; Ettenger, R.E.; Agodoa, L.Y.; Held, P.J.; Port, F.K. Comparison of mortality in all patients on dialysis, patients on dialysis awaiting transplantation, and recipients of a first cadaveric transplant. N. Engl. J. Med. 1999, 341, 1725-1730. [CrossRef] [PubMed]

10. Port, F.K.; Wolfe, R.A.; Mauger, E.A.; Berling, D.P.; Jiang, K. Comparison of survival probabilities for dialysis patients vs. cadaveric renal transplant recipients. JAMA 1993, 270, 1339. [CrossRef]

11. Gaston, R.S.; Danovitch, G.M.; Adams, P.L.; Wynn, J.J.; Merion, R.M.; Deierhoi, M.H.; Metzger, R.A.; Cecka, J.M.; Harmon, W.E.; Leichtman, A.B.; et al. The report of a national conference on the wait list for kidney transplantation. Am. J. Transplant. 2003, 3, 775. [CrossRef]

12. Held, P.J.; Turenne, M.N.; Liska, D.W.; Zobel, D.L.; Webb, R.L.; Alexander, S.R.; Jones, C. Treatment modality patterns and transplantation among the United States pediatric end-stage renal disease population: A longitudinal study. Clin. Transplant. 1991, 71-85. [PubMed]

13. Snyder, J.J.; Kasiske, B.L.; Gilbertson, D.T.; Collins, A.J. A comparison of transplant outcomes in peritoneal and hemodialysis patients. Kidney Int. 2002, 62, 1423-1430. [CrossRef] [PubMed]

14. Sanfilippo, F.P.; Vaughn, W.K.; Peters, T.G.; Shield, C.F.; Adams, P.L.; Lorber, M.I.; Williams, G.M. Factors affecting the waiting time of cadaveric kidney transplant candidates in the USA. JAMA 1992, 267, 247. [CrossRef] [PubMed]

15. Rigoni, M.; Torri, E.; Nollo, G.; Zarantonello, D.; Laudon, A.; Sottini, L.; Guarrera, G.M.; Brunori, G. Survival and time-totransplantation of peritoneal dialysis versus hemodialysis for ESRD patients: Competing-risks regression model in a single Italian center experience. J. Nephrol. 2017, 30, 441-447. [CrossRef]

16. Report CNT. 2019. Available online: http:/ / www.trapianti.salute.gov.it/ (accessed on 11 November 2021).

17. Kaplan, E.L.; Meier, P. Nonparametric estimation for incomplete observations. J. Am. Statist. Assoc. 1958, 53, 457-481. [CrossRef]

18. Bostock, I.C.; Alberu, J.; Arvizu, A.; Hernández-Mendez, E.A.; De-Santiago, A.; Gonzalez-Tableros, N.; López, M.; Castelán, N.; Contreras, A.G.; Morales-Buenrostro, L.E.; et al. Probability of deceased donor kidney transplantation based on \% PRA. Transpl. Immunol. 2013, 28, 154-158. [CrossRef]

19. Abecassis, M.; Bartlett, S.T.; Collins, A.J.; Davis, C.L.; Delmonico, F.L.; Friedewald, J.J.; Hays, R.; Howard, A.; Jones, E.; Leichtman, A.B.; et al. Kidney transplantation as primary therapy for end-stage renal disease: A National Kidney Foundation/Kidney Disease Outcomes Quality Initiative (NKF/KDOQITM) conference. Clin. J. Am. Soc. Nephrol. 2008, 3, 471-480. [CrossRef]

20. Knoll, G.; Cockfield, S.; Blydt-Hansen, T.; Baran, D.; Kiberd, B.; Landsberg, D.; Rush, D.; Cole, E. Canadian Society of transplantation consensus guidelines on eligibility for kidney transplantation. CMAJ 2005, 173, S1-S25. [CrossRef]

21. Huang, Y.; Samaniego, M. Preemptive kidney transplantation: Has it come of age? Nephrol. Ther. 2012, 8, 428-432. [CrossRef]

22. Moist, L.M.; Port, F.K.; Orzol, S.M.; Young, E.W.; Ostbye, T.; Wolfe, R.A.; Hulbert-Shearon, T.; Jones, C.A.; Bloembergen, W.E Predictors of loss of residual renal function among new dialysis patients. J. Am. Soc. Nephrol. 2000, 11, 556-564. [CrossRef] [PubMed]

23. Heaf, J.G.; Wehberg, S. Relative survival of peritoneal Dialysis and Hemodialysis Patients: Effect of Cohort and Mode of Dialysis Initiation. PLoS ONE 2014, 9, e90119. [CrossRef] [PubMed]

24. Martins, L.S.; Malheiro, J.; Pedroso, S.; Almeida, M.; Dias, L.; Henriques, A.C.; Silva, D.; Davide, J.; Cabrita, A.; Noronha, I.L.; et al. Pancreas-kidney transplantation: Impact of dialysis modality on the outcome. Transpl. Int. 2015, 28, 972-979. [CrossRef] [PubMed]

25. López-Oliva, M.O.; Rivas, B.; Pérez-Fernández, E.; Ossorio, M.; Ros, S.; Chica, C.; Aguilar, A.; Bajo, M.A.; Escuin, F.; Hidalgo, L.; et al. Pretransplant peritoneal dialysis relative to hemodialysis improves long-term survival of kidney transplant patients: A single-center observational study. Int. Urol. Nephrol. 2014, 46, 825-832. [CrossRef]

26. Tang, M.; Li, T.; Liu, H. A comparison of transplant outcomes in peritoneal and hemodialysis patients: A meta-analysis. Blood Purif. 2016, 42, 170-176. [CrossRef]

27. Dipalma, T.; Fernández-Ruiz, M.; Praga, M.; Polanco, N.; González, E.; Gutiérrez-Solis, E.; Gutiérrez, E.; Andrés, A. Pre-transplant dialysis modality does not influence short- or long-term outcome in kidney transplant recipients: Analysis of paired kidneys from the same deceased donor. Clin. Transplant. 2016, 30, 1097-1107. [CrossRef]

28. Kramer, A.; Jager, K.J.; Fogarty, D.G.; Ravani, P.; Finne, P.; Pérez-Panadés, J.; Prütz, K.G.; Arias, M.; Heaf, J.G.; Wanner, C.; et al. Association between pre-transplant dialysis modality and patient and graft survival after kidney transplantation. Nephrol. Dial. Transplant. 2012, 27, 4473-4480. [CrossRef]

29. Molnar, M.Z.; Mehrotra, R.; Duong, U.; Bunnapradist, S.; Lukowsky, L.R.; Krishnan, M.; Kovesdy, C.P.; Kalantar-Zadeh, K. Dialysis modality and outcomes in kidney transplant recipients. Clin. J. Am. Soc. Nephrol. 2012, 7, 332-341. [CrossRef] [PubMed]

30. Goldfarb-Rumyantzev, A.S.; Hurdle, J.F.; Scandling, J.D.; Baird, B.C.; Cheung, A.K. The role of pretransplantation renal replacement therapy modality in kidney allograft and recipient survival. Am. J. Kidney Dis. 2005, 46, 537-549. [CrossRef] [PubMed] 
31. Schwenger, V.; Döhler, B.; Morath, C.; Zeier, M.; Opelz, G. The role of pretransplant dialysis modality on renal allograft outcome. Nephrol. Dial. Transplant. 2011, 26, 3761-3766. [CrossRef]

32. Katznelson, S.; Bhaduri, S.; Cecka, J.M. Clinical aspects of sensitization. Clin. Transpl. 1997, 285-296. [PubMed]

33. Barama, A.; Oza, U.; Panek, R.; Belitsky, P.; MacDonald, A.S.; Lawen, J.; McAlister, V.; Kiberd, B. Effect of recipient sensitization (peak PRA) on graft outcome in haploidentical living related kidney transplants. Clin. Transplant. 2000, 14, 212-217. [CrossRef]

34. Gebel, H.M.; Bray, R.A.; Nickerson, P. Pre-transplant assessment of donor-reactive, HLA-specific antibodies in renal transplantation: Contraindication vs. risk. Am. J. Transpl. 2003, 3, 1488-1500. [CrossRef]

35. Tambur, A.R.; Leventhal, J.R.; Walsh, R.C.; Zitzner, J.R.; Friedewald, J.J. HLA- DQ barrier: Effects on cPRA calculations Transplantation 2013, 96, 1065-1072. [CrossRef] [PubMed]

36. Sapir-Pichhadze, R.; Tinckam, K.J.; Laupacis, A.; Logan, A.G.; Beyene, J.; Kim, S.J. Immune sensitization and mortality in Wait-Listed Kidney Transplant Candidates. J. Am. Soc. Nephrol. 2016, 27, 570-578. [CrossRef]

37. Registry, A. ANZDATA Report 2011 Chapter 8 Transplantation. 2012. Available online: https://www.anzdata.org.au/report/ anzdata-35th-annual-report-2012/ (accessed on 11 November 2021).

38. Faravardeh, A.; Eickhoff, M.; Jackson, S.; Spong, R.; Kukla, A.; Issa, N.; Matas, A.J.; Ibrahim, H.N. Predictors of graft failure and death in elderly kidney transplant recipients. Transplantation 2013, 96, 1089. [CrossRef] [PubMed]

39. Lim, W.H.; Chapman, J.R.; Wong, G. Peak panel reactive antibody, cancer, graft, and patient outcomes in kidney transplant recipients. Transplantation 2015, 99, 1043-1050. [CrossRef]

40. Wetmore, J.B.; Peng, Y.; Monda, K.L.; Kats, A.M.; Kim, D.H.; Bradbury, B.D.; Collins, A.J.; Gilbertson, D.T. Trends in anemia management practices in patients receiving hemodialysis and peritoneal dialysis: A retro- spective cohort analysis. Am. J. Nephrol. 2015, 41, 354-361. [CrossRef]

41. Hoogeveen, E.K.; Aalten, J.; Rothman, K.J.; Roodnat, J.I.; Mallat, M.J.; Borm, G.; Weimar, W.; Hoitsma, A.J.; de Fijter, J.W. Effect of Obesity on the Outcome of Kidney Transplantation: A 20-Year Follow-Up. Transplantation 2011, 91, 869-874. [CrossRef]

42. Streja, E.; Molnar, M.Z.; Kovesdy, C.P.; Bunnapradist, S.; Jing, J.; Nissenson, A.R.; Mucsi, I.; Danovitch, G.M.; Kalantar-Zadeh, K. Associations of Pretransplant Weight and Muscle Mass with Mortality in Renal Transplant Recipients. Clin. J. Am. Soc. Nephrol. 2011, 6, 1463-1473. [CrossRef]

43. Chan, W.L.W.; Bosch, J.A.; Jones, D.; McTernan, P.; Philips, A.; Borrows, R. Obesity in kidney transplantation. J. Ren. Nutr. 2014, 24, 1-12. [CrossRef] [PubMed]

44. Abedini, S.; Holme, I.; März, W.; Weihrauch, G.; Fellström, B.; Jardine, A.; Cole, E.; Maes, B.; Neumayer, H.H.; Grønhagen-Riska, C.; et al. Inflammation in Renal Transplantation. Clin. J. Am. Soc. Nephrol. 2009, 4, 1246-1254. [CrossRef] [PubMed]

45. Kaisar, M.O.; Armstrong, K.; Hawley, C.; Campbell, S.; Mudge, D.; Johnson, D.W.; Prins, J.B.; Isbel, N.M. Adiponectin is associated with cardiovascular disease in male renal transplant recipients: Baseline results from the LANDMARK 2 study. BMC Nephrol. 2009, 10, 29. [CrossRef] [PubMed]

46. Winkelmayer, W.C.; Schaeffner, E.S.; Chandraker, A.; Kramar, R.; Rumpold, H.; Sunder-Plassmann, G.; Födinger, M. A J-shaped association between high- sensitivity C-reactive protein and mortality in kidney transplant recipients. Transplant. Int. 2007, 20, 505-511. [CrossRef]

47. Chanouzas, D.; Ng, K.P.; Fallouh, B.; Baharani, J. What influ- ences patient choice of treatment modality at the pre-dialysis stage? Nephrol. Dial. Transpl. 2012, 27, 1542-1547. [CrossRef]

48. Frei, U.; Noeldeke, J.; Machold-Fabrizii, V.A.; Arbogast, H.; Margreiter, R.; Fricke, L.; Voiculescu, A.; Kliem, V.; Ebel, H.; Albert, U.; et al. Prospective age- matching in elderly kidney transplant recipients-A 5-year analysis of Eurotransplant Senior Program. Am. J. Transplant. 2008, 8, 50-57. [CrossRef] [PubMed]

49. Neri, F.; Furian, L.; Cavallin, F.; Ravaioli, M.; Silvestre, C.; Donato, P.; La Manna, G.; Pinna, A.D.; Rigotti, P. How does age affect the outcome of kidney transplantation in elderly recipients? Clin. Transplant. 2017, 31, e13036. [CrossRef]

50. United States Renal Data System. 2020 USRDS Annual Data Report: Epidemiology of Kidney Disease in the United States; National Institutes of Health, National Institute of Diabetes and Digestive and Kidney Diseases: Bethesda, MD, USA, 2020.

51. Chang, P.; Gill, J.; Dong, J.; Rose, C.; Yan, H.; Landsberg, D.; Cole, E.H.; Gill, J.S. Living donor age and kidney allograft half-life: Implications for living donor paired exchange programs. Clin. J. Am. Soc. Nephrol. 2012, 7, 835-841. [CrossRef] [PubMed]

52. Phelan, P.J.; O’Kelly, P.; O’Neill, D.; Little, D.; Hickey, D.; Keogan, M.; Walshe, J.; Magee, C.; Conlon, P.J. Analysis of waiting times on Irish renal Transplant list. Clin. Transpl. 2010, 24, 381-385. [CrossRef]

53. Ng, M.S.Y.; Ullah, S.; Wilson, G.; McDonald, S.; Sypek, M.; Mallett, A.J. ABO blood group relationships to kidney transplant recipient and graft outcomes. PLOS ONE 2020, 15, e0236396. [CrossRef] [PubMed] 